\title{
In the Realm of Psychoneuroimmunology: The Role of Celecoxib as an Add-On Treatment for Bipolar Mania
}

\author{
Mohammed Al-Alawi ${ }^{a, b}$ Hamed Al Sinawi ${ }^{a, b}$ Roshe Rashid ${ }^{b}$ \\ ${ }^{a}$ Oman Medical Specialty Board, Muscat, Oman; ${ }^{b}$ Department of Behavioral Medicine, Sultan Qaboos University \\ Hospital, Muscat, Oman
}

\section{Keywords}

Celecoxib · Bipolar disorder · Bipolar mania · Adjunctive treatment $\cdot$ Inflammatory response $\cdot$ Neuroimmunology

\begin{abstract}
Bipolar affective disorder (BPAD) is a chronic debilitating psychiatric illness seriously affecting the quality of patients' life. The available treatment is effective in about half of those suffering from the illness. The neurobiological basis of the disorder is not fully unraveled. With such lacunae, attempts have been made to decipher the underlying neuroimmunological process of the illness as is the case with other mental disorders. As a result, some inflammatory processes have been implicated in the etiology of BPAD, as described in this communication. Subsequently, the role of anti-inflammatory agents such as celecoxib was investigated by treating different phases of BPAD. Given the promising outcomes of several trials and reviews, celecoxib has gained momentum and has been recommended as an adjunctive treatment by some guidelines for treating resistant BPAD cases. This brief communication highlights some of the caveats in the randomized trials using celecoxib as an add-on treatment in bipolar mania specifically, which need to be addressed in future work.

(c) 2018 S. Karger AG, Basel
\end{abstract}

\section{Why Do We Need Another Drug?}

Bipolar affective disorder (BPAD) is a chronic psychiatric disease that affects the functionality of patients on a social, occupational, and personal level [1]. Furthermore, it also jeopardizes the patients' quality of life both medically and psychologically [1-3]. Approximately half of all $\mathrm{BPAD}$ patients respond positively to the currently available treatments (mood stabilizers, antipsychotics), with alternative therapies only helping a small percentage of patients $[1,4-8]$.

\section{What Is the Role of Psychoneuroimmunology in BPAD?}

The dysregulation of inflammatory responses has recently been implicated in the neuroimmunopathogenesis of mental disorders, specifically as an etiological factor in disorders such as BPAD, unipolar depression, and schizophrenia [9-17]. A recent study found that patients with bipolar disorder (BD) who are in manic or depressed states have higher levels of circulating, activated $\mathrm{T}$ cells and serum interleukin (IL)-2 receptors when compared to healthy controls $[18,19]$. In comparison to healthy con-

\section{KARGER}

(C) 2018 S. Karger AG, Basel

E-Mail karger@karger.com

www.karger.com/mnp
Mohammed Al-Alawi

Department of Behavioral Medicine, Sultan Qaboos University

PO Box 35, Al-Khoudh 123

Muscat 113 (Oman)

E-Mail alalawim@squ.edu.om 
trols, several studies have demonstrated that patients with BD have higher levels of serum inflammatory cytokines (IL-1, IL-6, and tumor necrosis factor [TNF]- $\alpha$ ). Patients with $\mathrm{BD}$ who are either in a manic or depressive state have shown an increased level of TNF- $\alpha$ and an upregulation of TNF-R1 and TNF-R2, as well as elevated levels of IL- 6 and C-reactive protein [20-22]. Furthermore, raised levels of serum IL-6 have been found to be correlated with the severity of structural and connectivity deficits in the brain circuitry of patients with $\mathrm{BD}[14,23]$. With regards to the inflammatory neurotoxic etiology of $\mathrm{BD}$, several studies have highlighted the role that lithium and other antipsychotics play in downregulating the expression of genes relating to inflammation and decreasing the production of inflammatory circulating cytokines [24-26]. Moreover, the administration of lithium for more than 3 months has been noted to result in the downregulation in the production of cytokines (IL-2, IL-6, IL-10, and IFN- $\gamma$ ) in stable BAD patients $[14,27]$. It is believed that the psychotropic drugs used to treat $\mathrm{BD}$ patients allow these patients to retain their ability to modify the proinflammatory cytokines and re-establish their inflammatory balance [28, 29].

\section{Do Mood Stabilizers Modulate the Inflammatory Response, and What Does This Signify?}

Independently, both Rapoport and Bosetti [30] in 2002 and Lee et al. [31] in 2007 demonstrated that mood stabilizers (lithium and anticonvulsants) downregulate the arachidonic acid chain reactions and reduce the production of phospholipase A2 (PLA2), brain cyclooxygenase-2 (COX2), and prostaglandin E2 in rats [30-33]. The therapeutic effects of anti-inflammatory drugs such as COX2 inhibitors, through their action on COX2, in improving the symptoms in $\mathrm{BD}$ patients have subsequently been tested [34].

Celecoxib is the first COX2-selective inhibitor to decrease the levels of proinflammatory prostaglandins and cytokines without causing toxic upper gastrointestinal side effects such as bleeding $[35,36]$. Regarding its cardiovascular safety, celecoxib was found to be superior to naproxen and ibuprofen $[37,38]$.

\section{Celecoxib as an Adjuvant Treatment Option for BPAD: The Facts}

Celecoxib has been used in some studies as a supplementary intervention to treat unipolar depression and it has been shown to have promising results with regard to early remission, improvement in depression measurement indices, and side-effect profiles according to a recent systemic review [39].

A recent systematic review of 8 randomized controlled trials (RCTs) investigating the efficacy and safety of supplementary anti-inflammatory treatments in bipolar depression found that the overall effect size on patients' depressive symptoms was -0.40 ( $95 \%$ confidence interval: -0.14 to $-0.65 ; p=0.002$ ), signifying moderate, yet statistically significant, antidepressant properties [40].

According to a double-blind, placebo-controlled RCT carried out by Nery et al. [41], BPAD patients with depressive or mixed episodes who were treated with celecoxib as an adjuvant treatment had an early remission of their depression. However, in the long term, the difference was not statistically significant between the study arms. In 2015, Arabzadeh et al. [42] conducted a doubleblind RCT to study the efficacy of celecoxib as an adjuvant treatment for acute mania in adults without psychosis over a 6-week period and found that there was a statistically significant high rate of early remission in the treatment arm compared to the placebo group. This RCT reported no severe side effects and found that celecoxib was well tolerated by those in the intervention arm.

One RCT conducted among a sample of Iranian adolescents with acute mania (without psychotic features) studying the efficacy and safety of celecoxib as an adjuvant therapy showed a statistically significant reduction ( $p=0.04)$ in Young Mania Rating Scale scores in the intervention group compared with the placebo group at week 8 [43].

\section{Current Treatment Guidelines for Celecoxib in BPADs and Caveats to Be Addressed in Future Work}

Lately, celecoxib was recognized, for the first time, as an alternative add-on treatment for bipolar mania, according to the 13th edition of Maudsley Prescribing Guidelines, one of the world's leading clinical references for psychotropic prescriptions [44]. However, this recommendation was based on one trail with constrained external validity, as it will be detailed below [42]. On the other hand, according to the Canadian Network for Mood and Anxiety Treatments and International Society for BPADs, celecoxib has not yet been appointed as an adjuvant treatment for BPAD patients, either in manic, mixed or depressive phases, despite promising findings from a number systematic reviews. Further studies are needed to create these guidelines [8]. Notably, in cases of unipolar 
depression, the British Association of Psychopharmacology recommends celecoxib as an alternative treatment in severe, resistant cases [45].

Overall, only two studies investigated the role of celecoxib as an adjuvant therapy in the treatment of acute mania. However, these studies have limited external validity due to their narrow inclusion criteria. For instance, Mousavi et al. [43] recruited only adolescents with acute mania, excluding those with psychosis, and Arabzadeh et al. [42] only included manic patients without psychosis. There is a high frequency in the number of occurrences of auditory hallucination, paranoid delusions, and Schneider's First Rank Symptoms in BPAD (18, 28, and 18\%, respectively), with about half of the patients having grandiose delusions [46]. However, the presence of psychosis does not automatically indicate the absence of capacity. Many patients with psychosis retain the ability to make informed choices and rational decisions. Therefore, excluding those with psychotic features may limit the gen- eralizability of results. Future work needs to overcome this limitation by including acute manic patients both with or without psychosis, while consciously assessing their capacity. Additionally, the effectiveness, pragmatism, duration of admission, the need for short-term sedative medications, and readmission rates have to be considered in future trials.

\section{Statement of Ethics}

This work adhered to the guidance of the World Medical Association's Declaration of Helsinki (1964-2008) for ethical human research.

\section{Disclosure Statement}

The authors declare that they have no conflicts of interest to disclose.

\section{References}

1 Dean OM, Gliddon E, Van Rheenen TE, Giorlando F, Davidson SK, Kaur M, et al. An update on adjunctive treatment options for bipolar disorder. Bipolar Disord. 2018 Mar; 20(2):87-96.

2 Esan O, Osunbote C, Oladele O, Fakunle S, Ehindero C, Fountoulakis KN. Bipolar I disorder in remission vs. schizophrenia in remission: is there a difference in burden? Compr Psychiatry. 2017 Jan;72:130-5.

3 Dargél AA, Masson M. Bipolar disorder: a single illness. Bipolar Disord. 2018 Apr;20(5): 492-3.

4 Passos IC, Kapczinski F. Should bipolar disorder treatment be modified depending on staging? Expert Rev Neurother. 2017 Feb; 17(2):93-5.

5 Malhi GS, Gessler D, Outhred T. The use of lithium for the treatment of bipolar disorder: recommendations from clinical practice guidelines. J Affect Disord. 2017 Aug;217:266-80.

6 Gershon S, Soares JC. Current therapeutic profile of lithium. Arch Gen Psychiatry. 1997 Jan;54(1):16-20.

7 Henter ID, Machado-Vieira R. The Treatment of Bipolar Disorder: Integrative Clinical Strategies and Future Directions. UK: Oxford University Press; 2017. p. 466.

8 Yatham LN, Kennedy SH, Parikh SV, Schaffer A, Bond DJ, Frey BN, et al. Canadian Network for Mood and Anxiety Treatments (CANMAT) and International Society for Bipolar Disorders (ISBD) 2018 guidelines for the management of patients with bipolar disorder. Bipolar Disord. 2018 Mar;20(2):97-170.
9 Wang AK, Miller BJ. Meta-analysis of cerebrospinal fluid cytokine and tryptophan catabolite alterations in psychiatric patients: comparisons between schizophrenia, bipolar disorder, and depression. Schizophr Bull. 2018 Jan;44(1):75-83.

10 Pasquali MA, Harlow BL, Soares CN, Otto MW, Cohen LS, Minuzzi L, et al. A longitudinal study of neurotrophic, oxidative, and inflammatory markers in first-onset depression in midlife women. Eur Arch Psychiatry Clin Neurosci. DOI:10.1007/s00406-017-0812-z.

11 Tatay-Manteiga A, Balanzá-Martínez V, Bristot G, Tabarés-Seisdedos R, Kapczinski F, Cauli O. Clinical staging and serum cytokines in bipolar patients during euthymia. Prog Neuropsychopharmacol Biol Psychiatry. 2017 Jul;77:194-201.

12 Müller N, Myint AM, Schwarz MJ. Inflammatory biomarkers and depression. Neurotox Res. 2011 Feb;19(2):308-18.

13 Mitchell RH, Goldstein BI. Inflammation in children and adolescents with neuropsychiatric disorders: a systematic review. J Am Acad Child Adolesc Psychiatry. 2014 Mar;53(3): 274-96.

14 Tu PC, Li CT, Lin WC, Chen MH, Su TP, Bai YM. Structural and functional correlates of serum soluble IL-6 receptor level in patients with bipolar disorder. J Affect Disord. 2017 Sep;219:172-7.

15 Müller N, Myint AM, Schwarz MJ. Inflammation in schizophrenia. Adv Protein Chem Struct Biol. 2012;88:49-68.
16 Rosenblat JD, Gregory JM, Flor-Henry S, McIntyre RS. Inflammation in Bipolar Disorder. In: Baune B. Inflammation and Immunity in Depression. Academic Press; 2018. p. 445-54.

17 Rosenblat JD, McIntyre RS. Bipolar Disorder and Immune Dysfunction: Epidemiological Findings, Proposed Pathophysiology and Clinical Implications. Brain Sci. 2017 Oct; 7(11): 144.

18 Husain MI, Strawbridge R, Stokes PR, Young AH. Anti-inflammatory treatments for mood disorders: systematic review and meta-analysis. J Psychopharmacol. 2017 Sep;31(9):113748.

19 Breunis MN, Kupka RW, Nolen WA, Suppes T, Denicoff KD, Leverich GS, et al. High numbers of circulating activated $\mathrm{T}$ cells and raised levels of serum IL-2 receptor in bipolar disorder. Biol Psychiatry. 2003 Jan;53(2): 157-65.

20 Eyler L, Dev S, Nguyen T, Gough S, Soontornniyomkij B, Sutherland A, et al. Elevations and Increased Variability of Blood-Based Pro-Inflammatory Markers among Patients with Bipolar Disorder. Biol Psychiatry. 2017 May;81(10):S120.

21 Herron JW, Nerurkar L, Cavanagh J. Neuroimmune biomarkers in mental illness. Curr Top Behav Neurosci. 2018 Apr; https:/doi. org/10.1007/7854_2018_45.

22 Edberg D, Hoppensteadt D, Walborn A, Fareed J, Sinacore J, Halaris A. Plasma C-reactive protein levels in bipolar depression during cyclooxygenase-2 inhibitor combination treatment. J Psychiatr Res. 2018 Jul;102:1-7. 
23 Data-Franco J, Singh A, Popovic D, Ashton $\mathrm{M}$, Berk M, Vieta E, et al. Beyond the therapeutic shackles of the monoamines: new mechanisms in bipolar disorder biology. Prog Neuropsychopharmacol Biol Psychiatry. 2017 Jan;72:73-86.

24 Hamdani N, Doukhan R, Kurtlucan O, Tamouza R, Leboyer M. Immunity, inflammation, and bipolar disorder: diagnostic and therapeutic implications. Curr Psychiatry Rep. 2013 Sep;15(9):387.

25 Vizlin-Hodzic D, Zhai Q, Illes S, Södersten K, Truvé K, Parris TZ, et al. Early onset of inflammation during ontogeny of bipolar disorder: the NLRP2 inflammasome gene distinctly differentiates between patients and healthy controls in the transition between iPS cell and neural stem cell stages. Transl Psychiatry. 2017 Jan;7(1):e1010.

26 van den Ameele S, van Diermen L, Staels W, Coppens V, Dumont G, Sabbe B, et al. The effect of mood-stabilizing drugs on cytokine levels in bipolar disorder: A systematic review. J Affect Disord. 2016 Oct;203:364-73.

27 Boufidou F, Nikolaou C, Alevizos B, Liappas IA, Christodoulou GN. Cytokine production in bipolar affective disorder patients under lithium treatment. J Affect Disord. 2004 Oct 82(2):309-13.

28 Goldstein BI, Kemp DE, Soczynska JK, McIntyre RS. Inflammation and the phenomenology, pathophysiology, comorbidity, and treatment of bipolar disorder: a systematic review of the literature. J Clin Psychiatry. 2009 Aug;70(8):1078-90.

29 da Costa SC, Machado-Vieira R, Soares JC. Novel Therapeutics in Bipolar Disorder. Curr Treat Options Psychiatry. 2018;5(1):162-81.

30 Rapoport SI, Bosetti F. Do lithium and anticonvulsants target the brain arachidonic acid cascade in bipolar disorder? Arch Gen Psychiatry. 2002 Jul;59(7):592-6.

31 Lee HJ, Rao JS, Rapoport SI, Bazinet RP. Antimanic therapies target brain arachidonic acid signaling: lessons learned about the regulation of brain fatty acid metabolism. Prostaglandins Leukot Essent Fatty Acids. 2007 Nov-Dec;77(5-6):239-46.

32 Rapoport SI. Lithium and the other mood stabilizers effective in bipolar disorder target the rat brain arachidonic acid cascade. ACS Chem Neurosci. 2014 Jun;5(6):459-67.

33 Husain MI, Chaudhry IB, Hamirani MM, Minhas FA, Kazmi A, Hodsoll J, et al. Minocycline and celecoxib as adjunctive treatments for bipolar depression: a study protocol for a multicenter factorial design randomized controlled trial. Neuropsychiatr Dis Treat. 2016 Dec;13:1-8.

34 Henter ID, Machado-Vieira R. Novel therapeutic targets for bipolar disorder. In: Carvalho AF, Vieta E, editors. The Treatment of Bipolar Disorder: Integrative Clinical Strategies and Future Directions. UK: Oxford University Press; 2017. p. 466.

35 McCormack PL. Celecoxib: a review of its use for symptomatic relief in the treatment of osteoarthritis, rheumatoid arthritis and ankylosing spondylitis. Drugs. 2011 Dec;71(18): 2457-89.

36 Shi S, Klotz U. Clinical use and pharmacological properties of selective COX-2 inhibitors. Eur J Clin Pharmacol. 2008 Mar;64(3):23352.

37 Nissen SE, Yeomans ND, Solomon DH, Lüscher TF, Libby P, Husni ME, et al.; PRECISION Trial Investigators. Cardiovascular safety of Celecoxib, naproxen, or ibuprofen for arthritis. N Engl J Med. 2016 Dec;375(26): 2519-29.

38 Kargar M, Yoosefi A, Akhondzadeh S, Artonian V, Ashouri A, Ghaeli P. Effect of adjunctive celecoxib on BDNF in manic patients undergoing electroconvulsive therapy: A randomized double blind controlled trial. Pharmacopsychiatry. 2015 Nov;48(7):268-73.

39 Kappelmann N, Lewis G, Dantzer R, Jones PB, Khandaker GM. Antidepressant activity of anti-cytokine treatment: a systematic review and meta-analysis of clinical trials of chronic inflammatory conditions. Mol Psychiatry. 2018 Feb;23(2):335-43.

40 Rosenblat JD, Kakar R, Berk M, Kessing LV, Vinberg M, Baune BT, et al. Anti-inflammatory agents in the treatment of bipolar depression: a systematic review and meta-analysis. Bipolar Disord. 2016 Mar;18(2):89-101.

41 Nery FG, Monkul ES, Hatch JP, Fonseca M, Zunta-Soares GB, Frey BN, et al. Celecoxib as an adjunct in the treatment of depressive or mixed episodes of bipolar disorder: a doubleblind, randomized, placebo-controlled study. Hum Psychopharmacol. 2008 Mar;23(2):8794.

42 Arabzadeh S, Ameli N, Zeinoddini A, Rezaei F, Farokhnia M, Mohammadinejad P, et al. Celecoxib adjunctive therapy for acute bipolar mania: a randomized, double-blind, placebo-controlled trial. Bipolar Disord. 2015 Sep; 17(6):606-14.

43 Mousavi SY, Khezri R, Karkhaneh-Yousefi MA, Mohammadinejad P, Gholamian F, Mohammadi MR, et al. A Randomized, DoubleBlind Placebo-Controlled Trial on Effectiveness and Safety of Celecoxib Adjunctive Therapy in Adolescents with Acute Bipolar Mania. J Child Adolesc Psychopharmacol. 2017 Aug; 27(6):494-500

44 Taylor D, Young A, Barnes T. The maudsley prescribing guidelines in psychiatry. Malden (MA): Wiley-Blackwell; 2018.

45 Cleare A, Pariante CM, Young AH, Anderson IM, Christmas D, Cowen PJ, et al.; Members of the Consensus Meeting. Evidence-based guidelines for treating depressive disorders with antidepressants: A revision of the 2008 British Association for Psychopharmacology guidelines. J Psychopharmacol. 2015 May; 29(5):459-525.

46 Goodwin FK, Jamison KR. Manic-Depressive Illness. New York: Oxford University Press; 1990. p. 186-209.
The Role of Celecoxib as an Add-On

Treatment for Bipolar Mania
Mol Neuropsychiatry 2018;4:164-167

DOI: $10.1159 / 000494700$ 